\title{
Article
}

\section{Low-Frequency Electrical Properties of Polycrystalline Saline Ice and Salt Hydrates}

Robert E. Grimm, David E. Stillman, Steven F. Dec, and Mark A. Bullock J. Phys. Chem. B, 2008, 112 (48), 15382-15390 • Publication Date (Web): 11 November 2008

Downloaded from http://pubs.acs.org on December 4, 2008

\section{More About This Article}

Additional resources and features associated with this article are available within the HTML version:

- $\quad$ Supporting Information

- $\quad$ Access to high resolution figures

- $\quad$ Links to articles and content related to this article

- $\quad$ Copyright permission to reproduce figures and/or text from this article

\section{View the Full Text HTML}




\title{
Low-Frequency Electrical Properties of Polycrystalline Saline Ice and Salt Hydrates
}

\author{
Robert E. Grimm, ${ }^{*},{ }^{\dagger}$ David E. Stillman, ${ }^{\dagger}$ Steven F. Dec, ${ }^{\ddagger}$ and Mark A. Bullock ${ }^{\dagger}$ \\ Department of Space Studies, Southwest Research Institute, 1050 Walnut St. No. 300, Boulder, Colorado 80302, and \\ Department of Chemistry and Geochemistry, Colorado School of Mines, Golden, Colorado 80401
}

Received: June 23, 2008; Revised Manuscript Received: August 25, 2008

\begin{abstract}
We measured the $1 \mathrm{mHz}-1 \mathrm{MHz}$ electrical properties of ice-hydrate binary systems formed from solutions of $\mathrm{NaCl}, \mathrm{CaCl}_{2}$, and $\mathrm{MgSO}_{4}$, with supplementary measurements of $\mathrm{HCl}$. Below the eutectic temperature, electrical parameters are well described by mixing models in which hydrate is always the connected phase. Above the eutectic temperature, a salt concentration threshold of $\sim 3 \mathrm{mM}$ in the initial solution is required for the unfrozen brine fraction to form interconnected, electrically conductive networks. The dielectric relaxation frequency for saline ice increases with increasing impurity content until $\mathrm{Cl}^{-}$reaches saturation. Because there is insufficient $\mathrm{H}_{3} \mathrm{O}^{+}$for charge balance, salt cations must be accommodated interstitially in the ice. Dielectric relaxations near the ice signature were identified for $\mathrm{CaCl}_{2} \cdot 6 \mathrm{H}_{2} \mathrm{O}$ and $\mathrm{MgSO}_{4} \cdot 11 \mathrm{H}_{2} \mathrm{O}$ but not for $\mathrm{NaCl} \cdot 2 \mathrm{H}_{2} \mathrm{O}$. Ionic and L-defect concentrations in salt hydrates up to $\sim 10^{-4}$ and $10^{-3}$ per $\mathrm{H}_{2} \mathrm{O}$ molecule, respectively, follow from the electrical properties, Jaccard theory, and the assumption that protonic-defect mobilities are similar to ice. These high defect concentrations - up to a few orders of magnitude greater than saturation values in ice-indicate that intrinsic disruption of hydrogen bonding in salt hydrates is common.
\end{abstract}

\section{Introduction}

Electrical-properties measurements have been a fundamental tool in understanding the structural chemistry of ice ${ }^{1}$ and the record of past environments in polar ice. ${ }^{2}$ These studies have mostly considered trace quantities of impurities that are able to substitute into the ice lattice. Conversely, electrical measurements of ice with high impurity content-where impurities are largely rejected to intergranular spaces - have focused on sea ice above or just below its eutectic-melting temperature. ${ }^{3}$ Our interest is in the context and behavior of ices and hydrates in a variety of natural terrestrial and planetary environments, so we seek to understand the electrical properties of $\mathrm{H}_{2} \mathrm{O}$ over wide ranges of temperature and impurity type and quantity. Studies of terrestrial permafrosts ${ }^{4,5}$ provide insights at the highest impurity levels and temperatures, yet these largely represent insoluble impurities (silicates). Measurement and analysis of systems of ice and salt hydrate are necessary to bridge the gap, followed by investigation of the interaction of these binary mixtures with silicates. Here we address the former and report broadband dielectric spectroscopy of polycrystalline ices and hydrates involving three geologically relevant salts: $\mathrm{NaCl}, \mathrm{CaCl}_{2}$, and $\mathrm{MgSO}_{4}$, with supplementary measurements of $\mathrm{HCl}$.

\section{Background}

The relevant electrical properties of ice and their origin are summarized from ref 1 and references therein. Two kinds of protonic point defects in the hydrogen-bonded ice lattice, each with two states, allow charge movement. Rotation of a water molecule produces a site with no protons (Bjerrum L-defect) and another with two (Bjerrum D-defect). Translation of protons along hydrogen bonds transfers ionization state by a charge surplus $\left(\mathrm{H}_{3} \mathrm{O}^{+}\right.$ionic defect $)$or deficit $\left(\mathrm{OH}^{-}\right.$ionic defect $)$. Defect

* Author to whom correspondence should be addressed. E-mail: grimm@boulder.swri.edu.

Southwest Research Institute.

$\ddagger$ Colorado School of Mines.
TABLE 1: Electrical Properties of Protonic Point Defects in Ice at $253 \mathrm{~K}^{1}$

\begin{tabular}{lcccc}
\hline defect & $\begin{array}{c}\text { effective } \\
\text { charge, e }\end{array}$ & $\begin{array}{c}\text { intrinsic concn, } \\
\text { per } \mathrm{H}_{2} \mathrm{O}\end{array}$ & $\begin{array}{c}\text { mobility, } \\
\mathrm{m}^{2} \mathrm{~V}^{-1} \mathrm{~s}^{-1}\end{array}$ & $\begin{array}{c}\text { activation } \\
\text { energy, }{ }^{a} \mathrm{eV}\end{array}$ \\
\hline $\mathrm{H}_{3} \mathrm{O}^{+}$ & +0.62 & $<10^{-13}$ & $10^{-7}$ & $\sim 0.7$ intrinsic \\
$\mathrm{L}$ & -0.38 & $10^{-7}$ & $2 \times 10^{-8}$ & $\sim 0.0$ extrinsic \\
& & & & $\sim 0.6$ intrinsic \\
& & & &
\end{tabular}

${ }^{a}$ Computed from activation energies of pair formation and motion.

types and abundances can be quantified from electrical-properties measurements through Jaccard theory ${ }^{1,6}$ (derived parameters reproduced in Table 1). For the dominant $\mathrm{H}_{3} \mathrm{O}^{+}$and L-defects, the relevant equations are

$$
\begin{gathered}
\sigma_{\mathrm{L}}=n_{\mathrm{L}} \mu_{\mathrm{L}} e_{\mathrm{L}} \\
\sigma_{+}=n_{+} \mu_{+} e_{+} \\
\sigma_{\infty}=\sigma_{\mathrm{L}}+\sigma_{+} \\
\frac{e^{2}}{\sigma_{\mathrm{s}}}=\frac{e_{\mathrm{L}}^{2}}{\sigma_{\mathrm{L}}}+\frac{e_{+}^{2}}{\sigma_{+}} \\
\frac{1}{\tau}=\Phi\left(\frac{\sigma_{\mathrm{L}}}{e_{\mathrm{L}}^{2}}+\frac{\sigma_{+}}{e_{+}^{2}}\right)=\frac{\sigma_{\infty}-\sigma_{\mathrm{s}}}{\varepsilon_{0}\left(\varepsilon_{\mathrm{s}}-\varepsilon_{\infty}\right)}
\end{gathered}
$$

where $\sigma_{\mathrm{L}}$ is the L-defect conductivity, proportional to the defect number density $n_{\mathrm{L}}\left(\mathrm{m}^{-3}\right)$, mobility $\mu_{\mathrm{L}}\left(\mathrm{m}^{2} \mathrm{~V}^{-1} \mathrm{~s}^{-1}\right)$, and charge $e_{\mathrm{L}}(\mathrm{C})$, with equivalent quantities expressed for $\mathrm{H}_{3} \mathrm{O}^{+}$defects; $\sigma_{\mathrm{s}}$ and $\sigma_{\infty}$ are the static (DC) and high-frequency conductivities, respectively; $\varepsilon_{\mathrm{s}}$ and $\varepsilon_{\infty}$ are the corresponding relative permittivities; $\epsilon_{0}$ is the permittivity of free space; and $\tau$ is the dielectric relaxation time. In this paper, we use "permittivity" without modification to indicate the real part of the relative permittivity, otherwise known as the dielectric constant. Similarly, "conductivity" implies the real part. The polarizability constant $\Phi=$ 
$\left(1.65 \times 10^{-32}\right) T(\mathrm{~K})$ provides the best match to $\varepsilon_{\mathrm{s}}-\varepsilon_{\infty}$ of pure ice $^{7}$ over the range 183 to $273 \mathrm{~K}$. The defect concentration per $\mathrm{H}_{2} \mathrm{O}$ molecule is $r=n / N$, where $N=3.061 \times 10^{28} \mathrm{H}_{2} \mathrm{O}$ molecules $/ \mathrm{m}^{3}$ for ice.

Equation 3 implies that the majority charge carrier dominates the high-frequency conductivity, because the polarization is continuously reversed. For pure ice, intrinsic Bjerrum defects are the majority charge carriers and intrinsic ionic defects are the minority. By contrast, eq 4 indicates that static conduction requires the motion of both Bjerrum and ionic defects, because polarization induced by passage of one kind of defect must be reversed by the other. The minority charge carrier therefore controls DC conduction. Equation 5 links the dispersion in conductivity to the dispersion in polarizability through a classic Debye relaxation.

Impurities that are able to substitute into the lattice structure introduce extrinsic protonic point defects, changing electrical properties. $\mathrm{HF}$ and $\mathrm{HCl}$ have been preferred dopants for studying the structural chemistry of ice because these acids are ready sources of $\mathrm{H}_{3} \mathrm{O}^{+}$defects and the small, easily substitutable halides engender numerous L-defects. ${ }^{8,9}$ Bases with substitutable cations (ammonia) have a similar effect. As $\mathrm{HF}$ or $\mathrm{HCl}$ levels are increased to just several $\mu \mathrm{M}$ at a few tens of kelvins below freezing, the increasing relative abundance of ionic defects causes a crossover in conductivities, where $\mathrm{H}_{3} \mathrm{O}^{+}$becomes the majority charge carrier and L-defects become the minority. ${ }^{8,9}$ Because acid $\left(\mathrm{H}_{3} \mathrm{O}^{+}\right)$concentration is generally much smaller than salt $\left(\mathrm{Cl}^{-}\right)$in polar ice, L-defects remain the majority charge carriers and no crossover has been observed in natural samples. ${ }^{2}$

In ice crystallizing from liquids, salts are presumed to affect $\sigma_{\mathrm{s}}$ by entering the lattice as an acid or base to maintain charge balance. ${ }^{10}$ For example, $\mathrm{NaCl}$ solutions are suggested to contribute $\mathrm{H}_{3} \mathrm{O}^{+}$and $\mathrm{Cl}^{-}$to the ice. Chloride substitution therefore must depend on the availability of hydronium and hence $\mathrm{pH}$, which we sought to characterize. On the other hand, flash-frozen $\mathrm{KOH}$ is thought to have $\mathrm{K}^{+}$accommodated interstitially, with $\mathrm{OH}^{-}$substituting directly in the lattice. ${ }^{11}$

Impurity saturation of the ice lattice has been determined ${ }^{12-14}$ to lie in the range $0.1-0.3 \mathrm{mM}$ for $\mathrm{Cl}^{-}$and $\mathrm{H}_{3} \mathrm{O}^{+}$. Impurities that cannot be incorporated into the ice are precipitated as hydrates. The unknown low-frequency electrical properties of salt hydrates and their relationships to ice are a major focus of this paper. These equilibrium-freezing relationships ${ }^{15-19}$ at high impurity content introduce additional electrical behaviors that we wished to measure. Below eutectic compositions (several $M$ for most salts) ice forms first and the excluded salt is concentrated into brines that freeze into an ice-hydrate mixture at the eutectic temperature (Figure 1a). Above the eutectic composition, hydrates form first and ice-hydrate mixture freezes last, again at the eutectic temperature. Initial salt concentrations are easily converted to relative weights of segregated ice and segregated hydrate by simple ratios involving the salt weight fraction at the eutectic $w^{\prime}$ and the salt weight fraction in the hydrate $w^{\prime \prime}$ (Table 2). The relative weight of the eutectic ice-hydrate mixture is the remainder from unity of the segregated ice and segregated hydrate weight fractions. The total hydrate weight is the segregated hydrate weight plus a fraction $\mathrm{W}_{\mathrm{H}}{ }^{\prime}$ of the eutectic mixture (Table 2). Volume conversions (Figure 1b,c) follow using the densities of ice $\left(915 \mathrm{~kg} \mathrm{~m}^{-3}\right.$ ) and hydrate (Table 2).

\section{Experimental Methods}

3.1. Electrical Properties. Measurements were performed from $1 \mathrm{mHz}$ to $1 \mathrm{MHz}$ with a Solartron 1260A Frequency
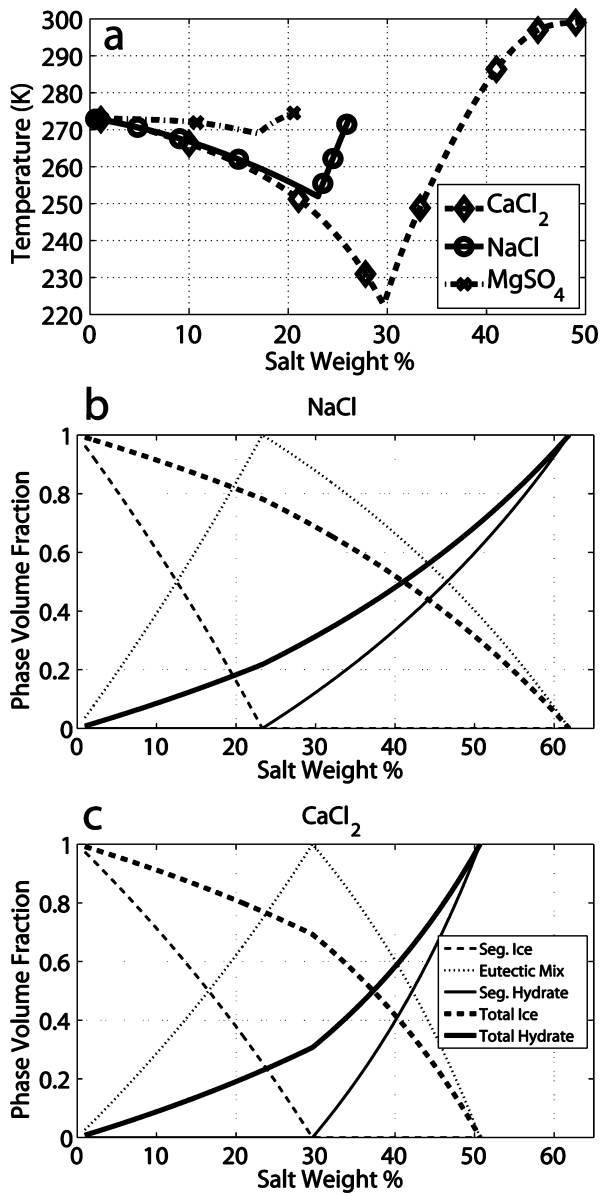

Figure 1. (a) Temperature-composition relations for freezing solutions of $\mathrm{NaCl}, \mathrm{CaCl}_{2}$, and $\mathrm{MgSO}_{4}$. Symbols show compositions of electricalproperties measurements. (b) Phase volume fractions as functions of initial salt concentration for $\mathrm{NaCl}$. (c) Phase volume fractions as functions of initial salt concentration for $\mathrm{CaCl}_{2}$.

Response Analyzer, 1296A Dielectric Interface, and a threeelectrode (capacitively coupled) sample holder. The third, grounded electrode was used as a guard to control electric-field geometry. The $1260 \mathrm{~A} / 1296 \mathrm{~A}$ system is rated at better than $2 \%$ accuracy for capacitances $>1 \mathrm{pF}$; all of our measurements met this criterion.

Solutions were prepared by using deionized (DI) water and reagent-grade salts, with approximate concentrations of $10^{-5}$, $10^{-3}, 10^{-2}, 10^{-1}$, and $1 \mathrm{M}$. Several additional measurements were performed for both $\mathrm{NaCl}$ and $\mathrm{CaCl}_{2}$ solutions at initial salt concentrations near and above the eutectic composition. The $\mathrm{CaCl}_{2}$ ice-hydrate system thus spanned compositions up to nearly $100 \% \mathrm{CaCl}_{2} \cdot 6 \mathrm{H}_{2} \mathrm{O}$. However, $\mathrm{NaCl} \cdot 2 \mathrm{H}_{2} \mathrm{O}$ was limited to a maximum volume of $\sim 25 \%$ because at higher initial salt concentrations the phase boundary ${ }^{16}$ is $>273 \mathrm{~K}$ and therefore we could not be sure that all $\mathrm{NaCl}$ was precipitated as hydrate. Similarly, the peritectic in the $\mathrm{MgSO}_{4}$ ice-hydrate system limited $\mathrm{MgSO}_{4} \cdot 11 \mathrm{H}_{2} \mathrm{O}$ to $42 \%$ by volume; otherwise epsomite would be initially precipitated. ${ }^{17}$ Actual ionic concentrations and $\mathrm{pH}$ of the melted samples were determined after the electrical experiments by standard inorganic analysis.

Samples were cylindrical disks, $3-\mathrm{cm}$ wide by $0.6-\mathrm{cm}$ thick. The sample holder was placed into a heavily insulated freezer (So-Low C85-9, minimum temperature $179 \mathrm{~K}$ ) and maintained to within $\pm 0.2 \mathrm{~K}$, using a Lakeshore 331 temperature controller. The time-temperature history was carefully constructed to produce quality polycrystalline materials. The samples were held 
TABLE 2: Properties of Frozen Salt-Water Binary Systems ${ }^{a}$

\begin{tabular}{|c|c|c|c|c|c|c|c|}
\hline salt & hydrate formula & hydrate name & $\begin{array}{l}\text { hydrate density, } \\
\qquad \mathrm{kg} \mathrm{m}^{-3}\end{array}$ & $\begin{array}{l}\text { eutectic } \\
\text { temp, K }\end{array}$ & $\begin{array}{l}\text { eutectic salt } \\
\text { wt } \%, w^{\prime}\end{array}$ & $\begin{array}{c}\text { eutectic hydrate, } \\
\text { wt } \%, w_{\mathrm{H}}^{\prime}\end{array}$ & $\begin{array}{c}\text { salt in hydrate, } \\
\text { wt } \%, w^{\prime \prime}\end{array}$ \\
\hline $\mathrm{CaCl}_{2}$ & $\mathrm{CaCl}_{2} \cdot 6 \mathrm{H}_{2} \mathrm{O}$ & Antarcticite & 1710 & 222 & 29.6 & 45.3 & 50.7 \\
\hline $\mathrm{NaCl}$ & $\mathrm{NaCl} \cdot 2 \mathrm{H}_{2} \mathrm{O}$ & Hydrohalite & 1610 & 252 & 23.3 & 32.9 & 61.9 \\
\hline
\end{tabular}

${ }^{a}$ At upper phase boundary for this hydrate. ${ }^{b}$ Scaled from unit cell volume.

2 deg below the freezing point for $1 \mathrm{~h}$ to start crystallization and then at $10 \mathrm{deg}$ below freezing for an additional $3 \mathrm{~h}$ to crystallize any metastable water. The sample was then reheated to $2 \mathrm{deg}$ below freezing and held for $3 \mathrm{~h}$ to facilitate annealing. This process was then repeated at the eutectic temperature for $\mathrm{NaCl}$ and $\mathrm{CaCl}_{2}$ solutions. Temperatures were decreased slowly $\left(0.1 \mathrm{deg} \mathrm{min}^{-1}\right)$ to impede bubble and crack formation (malformed samples were easily recognizable by extraneous dielectric dispersions). Temperatures were sampled at approximately logarithmic spacings except for smaller separations near the eutectic. Although hysteresis was generally small, measurements made during warming were preferred to those during freezing.

Complex impedances were converted to permittivity and phase by using the electrode geometry. For each spectrum, a nonlinear curve-fitting procedure was used to determine the parameters of up to four Cole-Cole dielectric relaxations, plus DC conductivity:

$$
\varepsilon^{*}=\varepsilon_{\mathrm{HF}}+\sum_{i} \frac{\Delta \varepsilon_{i}}{1+\left(i \omega \tau_{i}\right)^{1-\alpha_{i}}}-\frac{j \sigma_{\mathrm{DC}}}{\varepsilon_{0} \omega}
$$

where $\varepsilon^{*}=\varepsilon^{\prime}-j \varepsilon^{\prime \prime}$ is the complex permittivity, $\Delta \varepsilon_{i}, \tau_{i}$, and $\alpha_{i}$ are the dielectric strength, relaxation time, and distribution parameter, respectively, for the $i$ th dielectric relaxation, $\omega$ is the angular frequency, $\varepsilon_{\mathrm{HF}}$ is the "high-frequency" permittivity, and $\sigma_{\mathrm{DC}}$ is the DC conductivity. Note that $\alpha=0$ for a Debye relaxation. In addition to the ice and hydrate relaxations, other relaxations sometimes arose due to electrode polarization, malformed ice, or interfacial polarization. Measurements were included in subsequent analysis only when the ice/hydrate relaxation and DC conductivity could be robustly recovered (e.g., Figure 2). Increasing DC conductivity obscures relaxation signatures and introduces electrode polarization: measurements were stopped when the DC conductivity exceeded that measurable by the capacitively coupled system, $0.05 \mathrm{~S} \mathrm{~m}^{-1}$.

3.2. Unfrozen Water Content. The unfrozen water present in $\mathrm{H}_{2} \mathrm{O}$ - salt binary systems was measured by using nuclear magnetic resonance (NMR), from splits of samples prepared for electrical properties measurements. All ${ }^{1} \mathrm{H}$ NMR spectra were recorded on a Chemagnetics CMX Infinity 400 spectrometer operating at $400 \mathrm{MHz}$ for ${ }^{1} \mathrm{H}$. A Chemagnetics $7.5-\mathrm{mm}$ MAS probe was used to record nonspinning ${ }^{1} \mathrm{H}$ NMR spectra. Samples were contained in capped 5-mm NMR tubes, positioned in the probe such that the sample was in the center of the detection solenoid. To minimize proton background signals from the materials used to construct the probe, the DEPTH pulse sequence was used. ${ }^{20} 90^{\circ}$ pulses of $6.5 \mu$ s and a pulse repetition delay of $10 \mathrm{~s}$ were used. This pulse repetition delay provided quantitative peak integrals for the unfrozen water signal at all temperatures while minimizing the signal due to solid water. ${ }^{21}$ For 0.1 and $1 \mathrm{M}$ solutions, 16 transients were averaged, whereas 2048 transients were averaged for $1 \mathrm{mM}$ and $10 \mathrm{mM}$ solutions. At each temperature, the unfrozen water peak was integrated and corrected for the Boltzmann polarization. ${ }^{21}$
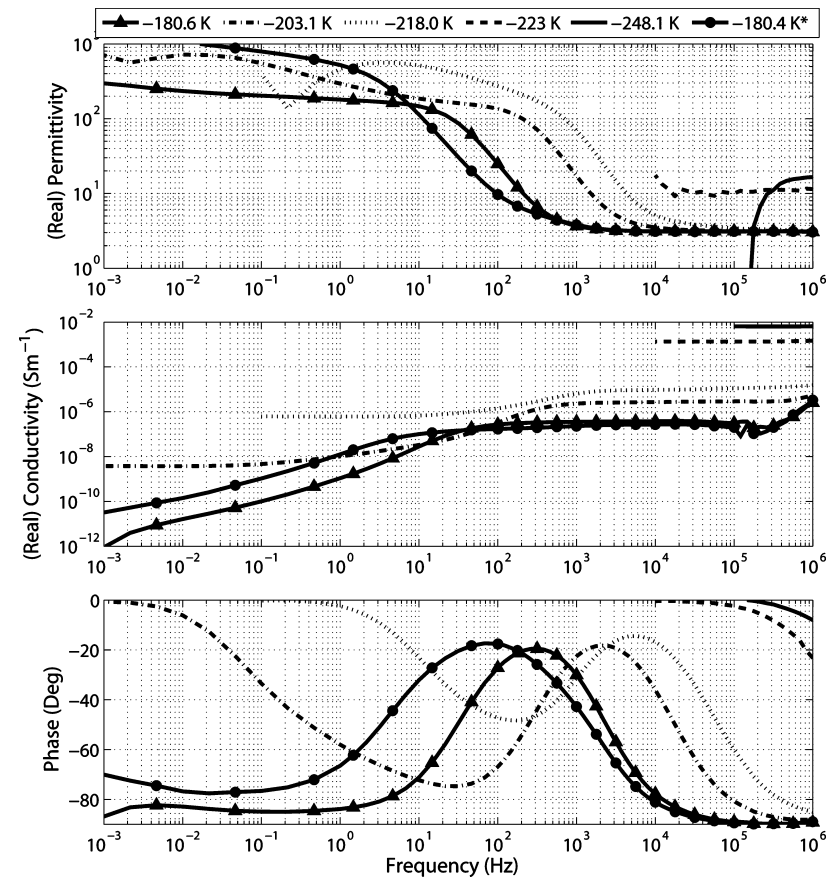

Figure 2. Dielectric spectrum of $1.1 \mathrm{wt} \%(0.1 \mathrm{M}) \mathrm{CaCl}_{2}$ solution as a function of temperature, with supplementary data for $0.011 \mathrm{wt} \%$ $(0.001 \mathrm{M}) \mathrm{CaCl}_{2}$ solution at $180.4 \mathrm{~K}$ only. Phase maximum moving from 0.3 to $5 \mathrm{kHz}$ is the Debye relaxation of ice; extraneous relaxation below $1 \mathrm{~Hz}$ is electrode polarization. The low-frequency increase in phase, becoming more prominent with increasing temperature, is due to DC conductivity. In particular, the large jump in DC conductivity from 218 to $223 \mathrm{~K}$ is caused by interconnected brine channels. The 0.011 wt $\% \mathrm{CaCl}_{2}$ data are representative of the decrease in relaxation frequency with decreasing impurity content.

\section{Results}

4.1. DC Conductivity. An initial steep decline in DC conductivity (Figure 3) just below $0{ }^{\circ} \mathrm{C}$ is attributable to premelting. ${ }^{22}$ Two regimes are evident at lower temperatures. Curves for lower initial salt concentrations have activation energies $E_{\mathrm{a}} \approx 0.7 \mathrm{eV}$, down to the lowest temperatures measured. However, curves for higher initial salt concentrations have smaller $E_{\mathrm{a}}=0.25-0.5 \mathrm{eV}$ down to the eutectic freezing point and increase to $\sim 1 \mathrm{eV}$ at lower temperatures. A distinct jump in DC conductivity is also evident at the eutectic for these curves. We attribute this difference to a salt concentration threshold for formation of interconnected brine channels. We quantify this assertion and then turn to the variation of DC conductivity with initial salt concentration at a representative temperature below the eutectic freezing point. In this case, where the entire mixture is frozen, the DC conductivity is taken to be equivalent to $\sigma_{\mathrm{s}}$.

4.1.1. Unfrozen Water Above Eutectic Melting Temperature. Here unfrozen saline water is expected around segregated ice or hydrates, depending on whether the initial concentration is below or above the eutectic composition, respectively. Computation of the unfrozen water volume fraction $\phi_{\mathrm{w}}$ is straightforward: ${ }^{23} \phi_{\mathrm{w}} \approx C_{0} / C_{\mathrm{eq}}$, where $C_{0}$ is the salt concentra- 

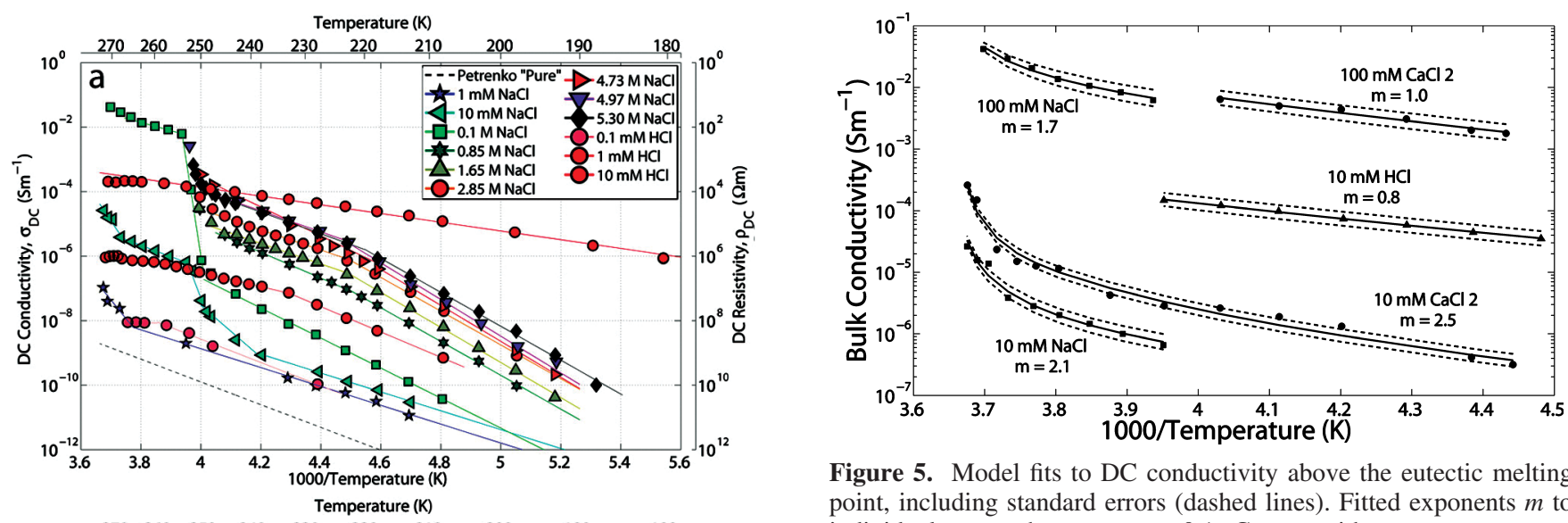

Figure 5. Model fits to DC conductivity above the eutectic melting point, including standard errors (dashed lines). Fitted exponents $m$ to individual curves have errors $<0.1$. Curves with measurements approaching $273 \mathrm{~K}$ show sharp increases in conductivity that are matched by $m=2.1 \pm 0.5$, characteristic of welded grains surrounded by moderately tortuous fluid channels. Fits to curves that do not approach ice melting show erroneously low exponents characteristic of parallel circuits.

water. The latter is computed by interpolating tabulations as functions of salt type, concentration, and temperature. ${ }^{19}$ This is a parallel circuit, ignoring any tortuosity or variable connectivity, and therefore is an upper bound to conductivity. Archie's law, $\sigma_{\mathrm{DC}}=\mathrm{A} \sigma_{\mathrm{w}} \phi_{\mathrm{w}}{ }^{m}$, is a more general empirical model that is applicable to poorly conducting grains with variable welding and geometry surrounded by a conductive fluid. Fits to ice-brine mixtures of $\mathrm{NaCl}, \mathrm{CaCl}_{2}$, and $\mathrm{HCl}$ (Figure 5) show that exponents $m$ lie in the range $0.8-2.5$. It is clear that data sets restricted to the broad, flatter parts of the curves $(100 \mathrm{mM}$ $\mathrm{CaCl}_{2}$ and $10 \mathrm{mM} \mathrm{HCl}$ ) show Archie exponents near unity, in apparent agreement with the parallel-circuit model. These measurements were truncated because conductivities and/or electrode polarizations were too large at higher temperatures to produce useful data in our capacitively coupled measurement system. In contrast, the remaining curves, which track closer to complete melting, have larger exponents, $m=2.1 \pm 0.5$. An Archie exponent of 2 is common for brines filling moderately welded sandstones. ${ }^{24}$ This natural analogue enables us to envision the active brine channels not uniquely as sheets separating two grains nor as tubes along triple junctions, but rather as a moderately tortuous, intermediate geometry. The rapid increase in conductivity near complete melting was previously explicitly neglected ${ }^{23}$ because it cannot be modeled linearly; an Archie model encompassing this premelting region demonstrates the nonlinear relationship between unfrozen water volume and DC conductivity.

A consistent threshold exists for the persistence of brine

Figure 4. NMR-observed (symbols) vs predicted (lines) liquid volume fraction for $\mathrm{CaCl}_{2}$ solutions above the eutectic melting temperature.

tion in the initial liquid and $C_{\mathrm{eq}}$ is the equilibrium salt concentration as a function of temperature, ${ }^{15-19}$ given by the phase diagrams (Figure 1). The predicted liquid fractions for initial $\mathrm{CaCl}_{2}$ concentrations of $0.01,0.1$, and $1 \mathrm{M}$ compare well with NMR measurements (Figure 4).

Since the expected liquid content is present, the geometry and connectivity can be revealed from variations in the DC conductivity with temperature and initial salt concentration. The conductivity of ice can be neglected compared to that of the unfrozen water in mixing models. A classic model for polar ice ${ }^{23}$ used the geometric cross section of assumed interconnected water channels on the surfaces of cubic grains to derive $\sigma_{\mathrm{DC}}=2 /{ }_{3} \sigma_{\mathrm{w}} \phi_{\mathrm{w}}$, where $\sigma_{\mathrm{w}}$ is the conductivity of the

channels down to the eutectic temperature. Initial concentrations of $\mathrm{NaCl}, \mathrm{CaCl}_{2}$, and $\mathrm{HCl}$ of $1 \mathrm{mM}$ do not support interconnected liquid at the respective eutectic temperatures, but concentrations of $10 \mathrm{mM}$ do. A supplemental measurement of $3 \mathrm{mM} \mathrm{CaCl} 2$ displays a small conductivity increase attributable to interconnected liquid. We therefore suggest that $3 \mathrm{mM}$ is a representative value for the brine channel threshold in ice containing salts or weak acids and formed from liquid. The $\mathrm{HCl}$ data do indicate interconnected brine channels at concentrations as low as 0.1 $\mathrm{mM}$, but in this case are limited to temperatures above $\sim 260$ $\mathrm{K}$. Brine exists only as isolated pockets at lower concentrations and/or temperatures.

Brine channel dimensions can be approximately calculated by using simple assumptions about their geometry. For ice grains of diameter $D$ modeled as truncated semiregular octahedra, ${ }^{25}$ 
TABLE 3: Computed Minimum Brine Channel Widths ${ }^{a}$

\begin{tabular}{cccc}
\hline impurity & $\begin{array}{c}\text { ice three-grain } \\
\text { junction dia., } \mu \mathrm{m}\end{array}$ & $\begin{array}{c}\text { ice two-grain } \\
\text { junction dia., } \mu \mathrm{m}\end{array}$ & $\begin{array}{c}\text { geometric } \\
\text { mean, } \mu \mathrm{m}\end{array}$ \\
\hline $\mathrm{CaCl}_{2}$ & 12 & 0.28 & 1.8 \\
$\mathrm{NaCl}$ & 8.4 & 0.14 & 1.1 \\
$\mathrm{HCl}$ & 7.8 & 0.12 & 1.0
\end{tabular}

${ }^{a}$ At respective eutectic temperatures, $3 \mathrm{mM}$ impurity threshold, and $1 \mathrm{~mm}$ ice grains.

the diameter $d_{3}$ of cylindrical triple junctions on the grain edges is $d_{3}=0.3874 D \sqrt{ } \phi_{\mathrm{w}}$. The same approach leads to $d_{2}=$ $0.2987 D \phi_{\mathrm{w}}$ for the thickness $d_{2}$ of two-grain planar junctions on the octahedra faces. We take the geometric mean of these two models, $d=0.34 D \phi_{\mathrm{w}}{ }^{3 / 4}$, as representative of brine channel width $d$ in an intermediate geometry. For our laboratory-grown, polycrystalline ice, $D \approx 1 \mathrm{~mm}$, so $d$ is in the micron range just above the eutectic temperatures of $\mathrm{CaCl}_{2}, \mathrm{NaCl}$, and $\mathrm{HCl}$ (Table 3 ). Persistence of acid-brine channels at $\mu \mathrm{M}$ bulk impurity levels in polar ice ${ }^{23}$ implies $d \approx 2 \mathrm{~nm}$, an implausibly small dimension that is only a handful of water molecules wide. If DC conduction in polar ice is through such acid-brine channels, a robust triple-junction geometry must exist so that $d_{3} \approx 0.1 \mu \mathrm{m}$.

There is support in other data for a brine channel threshold. The linear increase in $\sigma_{\infty}$ with salt content $C$ in polar ice is truncated at $C \approx 0.3 \mathrm{mM}$, the chloride saturation limit. ${ }^{10,11}$ Conductivity does not increase again until $C>30 \mathrm{mM}$, where natural and artificial sea ice were compared to a power-law that is equivalent to Archie exponent $m=2$ and was inferred to be caused by the formation of continuous liquid networks. ${ }^{13}$ The decade-lower impurity-concentration threshold for our results is likely due to the greater regularity of crystal formation and associated interconnected liquid junctions in the laboratory.

4.1.2. Ice-Hydrate Mixtures Below Eutectic Melting Temperature. We evaluated several classic electrical mixing models $^{26}$ at $208 \mathrm{~K}$, a representative temperature below all of the relevant salt eutectics. Because $\varepsilon^{\prime \prime} \approx \sigma / \varepsilon_{0} \omega \gg \varepsilon^{\prime}$ at low frequency, we solve the mixing equations directly in terms of $\sigma$ instead of $\varepsilon^{*}$. The Maxwell Garnett (MG) model treats isolated inclusions in a connected host medium. It will be useful here to give the MG conductivity in terms of the connected phase having conductivity $\sigma_{1}$ and volume abundance $\phi$ :

$$
\sigma=\sigma_{1}+\frac{1-\phi}{\frac{1}{\sigma_{2}-\sigma_{1}}+\frac{\phi}{3 \sigma_{1}}}
$$

Equation 7 is actually expressed in the form of the equivalent Hashin-Shtrikman upper bound. Power law (PL) mixing models enjoy wide empirical application but lack the physical underpinning of the MG rule; in effect, each phase is assumed to be interconnected with efficiency depending on the exponent $m$. The general PL for two phases is:

$$
\sigma^{1 / m}=\phi \sigma_{1}^{1 / m}+(1-\phi) \sigma_{2}^{1 / m}
$$

Commonly $m=1-3$ : MG is approximated at $m=1$, the Refractive Index model is equivalent to $m=2$, and the Looyenga model has $m=3$. If $\sigma_{2}=0$, Archie's law is recovered.

We fit the MG and PL models separately to data below and above the eutectic composition for frozen $\mathrm{CaCl}_{2}$ and $\mathrm{NaCl}$ solutions (Figure 6). For the MG model, the surrounding phase was assumed to be either the eutectic mixture or the total hydrate present. Both fit equally well below the eutectic composition,

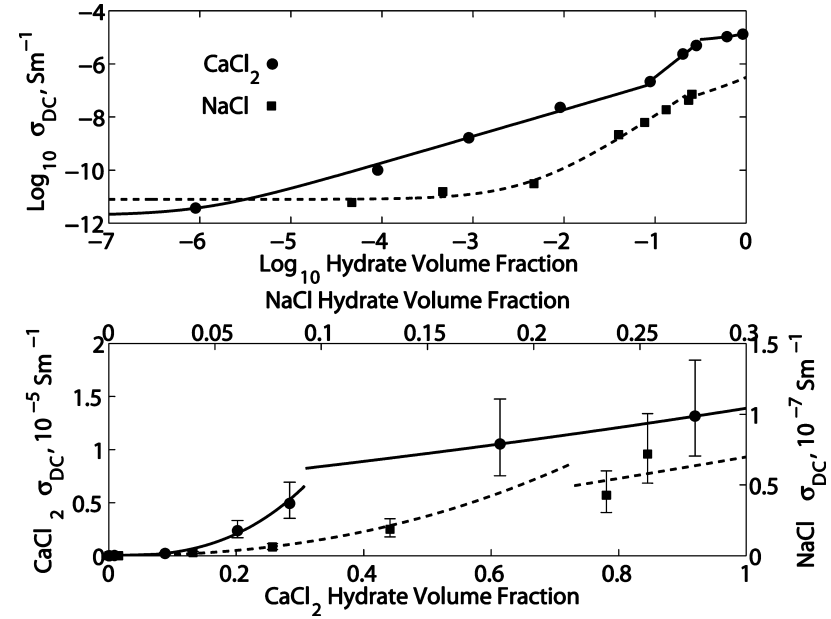

Figure 6. DC conductivity of ice-hydrate systems at $208 \mathrm{~K}$ : (a) logarithmic and (b) linear scales. Mixing models (lines) are fit separately to data below and above the eutectic composition, resulting in minor mismatches at the eutectic. All data are consistent with hydrate as the interconnected phase. See text for details.

but above the eutectic the conductivity-composition trend would reverse if the last-crystallized eutectic mixture was the connected phase. Instead, the conductivity continues to increase because the segregated hydrate must make good electrical contact with hydrate in the eutectic mixture. Therefore we conclude that all hydrate is electrically connected in the MG model, i.e., all ice exists as inclusions. This inference is supported by SEM imaging of ice-hydrate eutectic mixtures. ${ }^{27}$

The $\mathrm{NaCl}$ data are best fit (Figure 6) by a PL with $m=2.3$ \pm 0.3 for all subeutectic hydrate volumes (salt weight $w<23 \%$ ). This is similar to the behavior described above of brine channel conductivity above the eutectic melting temperature. Indeed, the geometries may be expected to be closely related because brine channels ultimately freeze into the eutectic mixture containing interconnected hydrate. In contrast, the $\mathrm{CaCl}_{2}$ data below the eutectic composition show two distinct branches: $\mathrm{MG}$ mixing up to $10 \%$ hydrate volume $(w<9 \%)$ and $m=2.7 \pm$ 0.2 PL above. Paradoxically, at low salt concentrations the ice is electrically included, whereas at higher concentrations the familiar power law indicates a more complex geometry.

Above the eutectic composition, the $\mathrm{CaCl}_{2}$ data are perfectly fit by the MG model, whereas the $\mathrm{NaCl}$ data can only be said to be consistent with MG within the measurement errors. The steep slope of a PL fit to these sparse $\mathrm{NaCl}$ data implies an unrealistically large conductivity for the pure hydrate and an unacceptably large mismatch at the eutectic composition. The conductivity of the eutectic mixture is an endmember for both supereutectic and subeutectic composition fits. For both salts, the preferred mixing models, fit separately below and above the eutectic composition, result in misfits at the eutectic of $<30 \%$.

The mixing models at $208 \mathrm{~K}$ projected to $100 \%$ hydrate yield $\sigma_{\mathrm{DC}}=1.4 \pm 0.7 \times 10^{-5} \mathrm{~S} \mathrm{~m}^{-1}$ for $\mathrm{CaCl}_{2} \cdot 6 \mathrm{H}_{2} \mathrm{O}$ and $3.1 \times$ $10^{-7} \mathrm{~S} \mathrm{~m}^{-1}$ for $\mathrm{NaCl} \cdot 2 \mathrm{H}_{2} \mathrm{O}$. Unlike the high-temperature cases where highly conductive fluid is present, the DC conductivity of the included ice is also recovered, here $8 \pm 2 \times 10^{-12} \mathrm{~S}$ $\mathrm{m}^{-1}$ for the $\mathrm{NaCl}$ experiments and $2.0 \pm 0.4 \times 10^{-12} \mathrm{~S} \mathrm{~m}^{-1}$ for the $\mathrm{CaCl}_{2}$ runs. Implications of these figures for ionic substitution and defects in the ice and hydrates are discussed below.

The reagent grade $\mathrm{MgSO}_{4}$ we tested contained significant amounts of chloride $\left(0.4\right.$ wt $\%$ in $1 \mathrm{M} \mathrm{MgSO}_{4}$ solutions, 


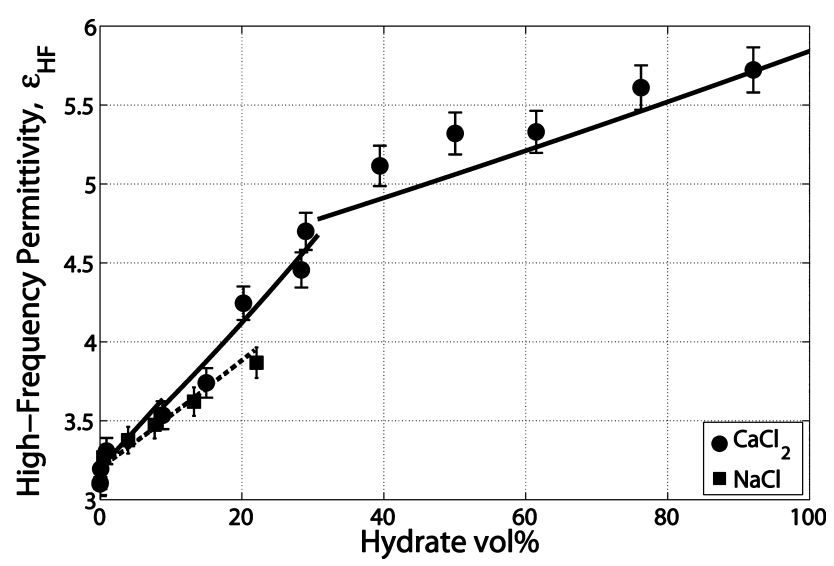

Figure 7. High-frequency permittivity of ice-hydrate systems at 1 $\mathrm{MHz}$, likely equivalent to postrelaxation $\varepsilon_{\infty}$. Data are shown at $181 \mathrm{~K}$ but temperature dependence is very weak. The same mixing models, with hydrate always as the connected phase, are fit to the same data segments as for the DC conductivity (see text). Value for ice is fixed at 3.15 and $\varepsilon_{\mathrm{HF}} \sim 5.8$ for $\mathrm{CaCl}_{2} \cdot 6 \mathrm{H}_{2} \mathrm{O}$ is fit.

increasing to $7 \mathrm{wt} \%$ at $1 \mathrm{mM} \mathrm{MgSO}_{4}$ ). DC conductivity curves for $\mathrm{MgSO}_{4}$ expressed in terms of chloride weight percent closely tracked those for $\mathrm{CaCl}_{2}$, indicating that antarcticite had formed and had conductivity greatly exceeding meridianiite. Indeed, below $1 \mathrm{M} \mathrm{MgSO}_{4}$, the calcium and chloride are present in approximately the correct proportions for $\mathrm{CaCl}_{2}$. If the conductivity of $\sim 1 \% \mathrm{CaCl}_{2} \cdot 6 \mathrm{H}_{2} \mathrm{O}$ in the mixture is still at least ten times that of $\sim 10 \% \mathrm{MgSO}_{4} \cdot 11 \mathrm{H}_{2} \mathrm{O}$, then we can crudely constrain $\sigma_{\mathrm{DC}}$ for $\mathrm{MgSO}_{4} \cdot 11 \mathrm{H}_{2} \mathrm{O}$ to be $<1 \%$ that of $\mathrm{CaCl}_{2}$. $6 \mathrm{H}_{2} \mathrm{O}$, say $<10^{-7} \mathrm{~S} / \mathrm{m}$ at $208 \mathrm{~K}$. Therefore the DC conductivity of meridianiite is likely less than that of hydrohalite.

4.2. Permittivity. 4.2.1. High Frequency. The real permittivity $\varepsilon^{\prime}$ generally asymptotes above $100 \mathrm{kHz}$ (Figure 2), so the fit value $\varepsilon_{\mathrm{HF}}$ is representative of $\varepsilon_{\infty}$ of the highest frequency relaxation. The same mixing equations (eqs 7 and 8) are applied with $\varepsilon^{\prime}$ substituted for $\sigma$. In this case the imaginary part is neglected because $\varepsilon^{\prime \prime} \ll \varepsilon^{\prime}$ as $\omega \rightarrow \infty$. As with DC conductivity, below the eutectic composition the models cannot discriminate whether the hydrate or eutectic mix is interconnected, but again we reason that hydrate must be the interconnected phase due to diminishing quantities of the eutectic mixture above the eutectic composition. Due to the smaller dynamic range in $\varepsilon^{\prime}$ compared to $\sigma_{\mathrm{DC}}$, there is also less discrimination between MG and PL mixing models; Figure 7 fits power laws to the subeutectic compositions of frozen $\mathrm{NaCl}$ and $\mathrm{CaCl}_{2}$ solutions with the same exponents (2.3 and 2.7, respectively) as DC conductivity. The $\mathrm{H}_{2} \mathrm{O}$ endmember was fixed at $3.15 . \mathrm{CaCl}_{2}$ measurements spanned nearly the entire range of composition above the eutectic; a MG mixing model with interconnected hydrate (the same as $\sigma_{\mathrm{DC}}$ ) yields $\varepsilon_{\mathrm{HF}}=5.8$ for $\mathrm{CaCl}_{2} \cdot 6 \mathrm{H}_{2} \mathrm{O}$. $\varepsilon_{\mathrm{HF}}$ was irregular for the narrow range of $\mathrm{NaCl}$ compositions measured above the eutectic composition, but the $\mathrm{CaCl}_{2}$ trend extrapolates to $\varepsilon_{\mathrm{HF}}=5.2$ for $\mathrm{NaCl} \cdot 2 \mathrm{H}_{2} \mathrm{O}$.

The $\mathrm{MgSO}_{4}-\mathrm{H}_{2} \mathrm{O}$ system yielded $\varepsilon_{\mathrm{HF}}=3.1$ for 42 vol $\%$ meridianiite, indicating that $\varepsilon_{\infty}$ for ice and this $\mathrm{H}_{2} \mathrm{O}$-rich hydrate are comparable. This suggests that antarcticite and hydrohalite could have another dielectric relaxation, beyond the measured band, in which $\Delta \varepsilon \approx 2-3$. A reversal in the phase trend would be evident in the $181 \mathrm{~K}$ data for any relaxation frequency $<8$ $\mathrm{MHz}$. When projected to $273 \mathrm{~K}$ at $E_{\mathrm{a}}=0.3 \mathrm{eV}$, the additional relaxation would have to be $>4.6 \mathrm{GHz}$. The relaxation frequency of liquid water is $8.9 \mathrm{GHz}$ at this temperature. Because it is

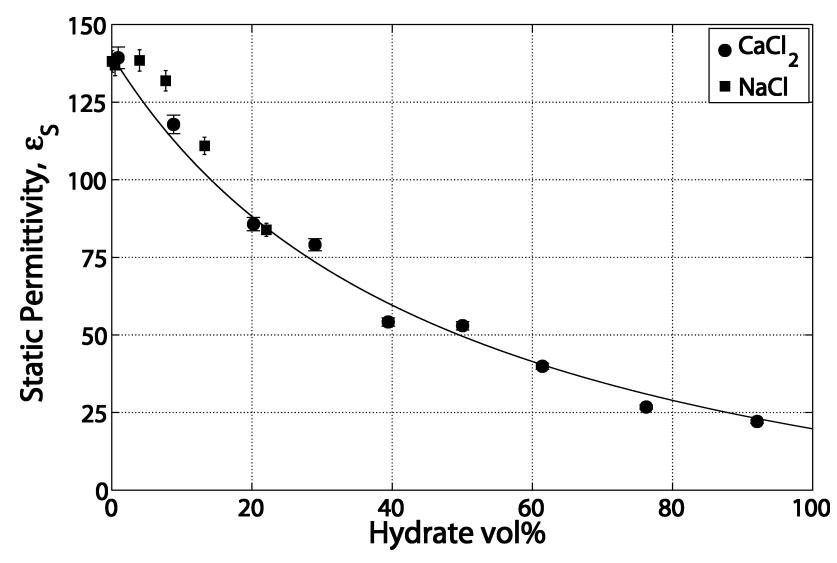

Figure 8. Low-frequency permittivity $\varepsilon_{\mathrm{s}}$ at $181 \mathrm{~K}$. Temperature dependence is strong and data are shown at the coldest temperature tested, where electrode polarization is minimized. For $\mathrm{CaCl}_{2}$ solutions, the Maxwell Garnett mixing model assumes hydrate is the connected phase: value for ice is fixed at 144 and $\varepsilon_{\mathrm{s}} \approx 20$ for $\mathrm{CaCl}_{2} \cdot 6 \mathrm{H}_{2} \mathrm{O}$ is fit. Incomplete $\mathrm{NaCl}$ data were not fit.

implausible that $\mathrm{H}_{2} \mathrm{O}$ mobility in the hydrate could approach that of free water, we conclude that $\varepsilon_{\mathrm{HF}}=\varepsilon_{\infty}$ for the salt hydrates.

4.2.2. Low Frequency. The $\mathrm{H}_{2} \mathrm{O}$-endmember value $\varepsilon_{\mathrm{s}}=144$ at $181 \mathrm{~K}$ is exactly that expected for "pure" ice. In fact this simply implies ${ }^{1}$ that $\sigma_{\mathrm{L}} \gg \sigma_{+}$and indicates that ice formed from saline solutions contains much more $\mathrm{Cl}^{-}$in the lattice than $\mathrm{H}_{3} \mathrm{O}^{+}$. We explore this further below in the context of relaxation times.

Dielectric mixing of $\mathrm{H}_{2} \mathrm{O}$ and $\mathrm{CaCl}_{2} \cdot 6 \mathrm{H}_{2} \mathrm{O}$ is consistent with the MG model assuming interconnected hydrate across the entire range of composition (Figure 8), with $\varepsilon_{\mathrm{s}}=20$ fit at $181 \mathrm{~K}$ for antarcticite. Therefore $\Delta \varepsilon=\varepsilon_{\mathrm{s}}-\varepsilon_{\infty}=14$. Data for other salt hydrates are incomplete, but $\varepsilon_{\mathrm{s}}=5.2$ for $22 \mathrm{vol} \%$ hydrohalite indicates no dielectric relaxation detected, whereas $\varepsilon_{\mathrm{s}}=7.9$ for $42 \mathrm{vol} \%$ meridianiite implies $\Delta \varepsilon>4.8$ for that hydrate. Static permittivities for the salt-ice binary mixtures are strongly temperature dependent, as is also observed for ice. ${ }^{7}$

4.3. Dielectric Relaxation Times. 4.3.1. Doped Ice. The relaxation time $\tau$ for ice increases with decreasing temperature and decreases with increasing impurity content (Figures 9-11). Pure ice has an activation energy $E_{\mathrm{a}} \approx 0.58 \mathrm{eV} .{ }^{28}$ An inflection to $E_{\mathrm{a}} \approx 0.24 \mathrm{eV}^{29,30}$ has been ascribed ${ }^{1}$ to impurities but not quantified. Our measured relaxation times decrease until a saturation limit is reached, where $E_{\mathrm{a}}$ has increased slightly to $\sim 0.29 \mathrm{eV}$.

We infer defect properties of the ice from the behavior of the relaxation time alone. First consider the relaxation of "pure" ice at $253 \mathrm{~K}$. Here $\tau=0.15 \mathrm{~ms}$ (Figure $9 \mathrm{a}$ ) and assuming $\sigma_{\mathrm{L}} \gg$ $\sigma_{+}$, it follows from eqs 5 and 1 that $r=1.6 \times 10^{-7}$ per $\mathrm{H}_{2} \mathrm{O}$ molecule. Because the intrinsic defect concentration is $\sim 10^{-7} /$ $\mathrm{H}_{2} \mathrm{O}$, the relaxation time is consistent, within measurement error, with conductivity dominated by the intrinsic L-defects.

The relaxation time of ice saturates for initial salt concentrations between 0.1 and $1 \mathrm{M}$ for both $\mathrm{NaCl}$ and $\mathrm{CaCl}_{2}$. We interpolate the saturation value to be $\sim 0.3 \mathrm{M}$ in the initial solution for purposes of the following calculations. We again neglect ionic defects and assume that each chloride ion contributes two L-defects (see Discussion). At $\mathrm{NaCl}$ saturation, $\tau=6 \mu$ s at $253 \mathrm{~K}$ (Figure 9 a) yields $r=4.0 \times 10^{-6} / \mathrm{H}_{2} \mathrm{O}$, or extrinsic L-defects now totaling about 40 times intrinsic. This corresponds to a chloride saturation concentration in ice $\sim 0.1$ $\mathrm{mM}$, equal to or less than earlier estimates, ${ }^{12,13}$ and implies a 

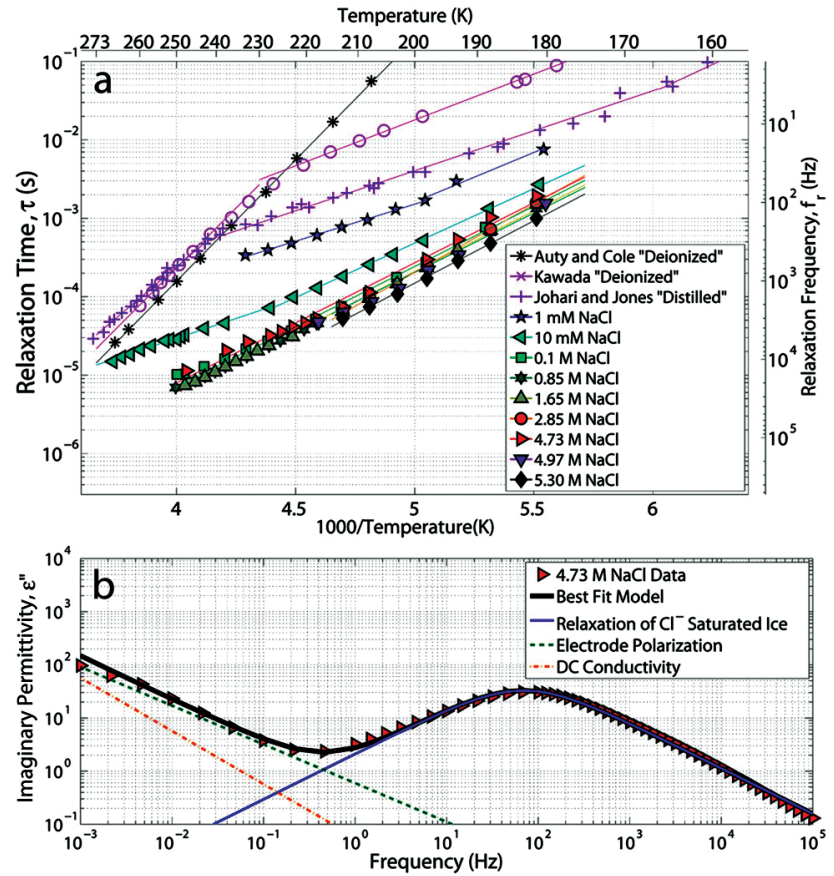

Figure 9. (a) Relaxation time for $\mathrm{NaCl}$-doped ice as functions of temperature and initial solution salt concentration, compared to measurements for "pure" ice from the literature. Concentrations are reported for the initial solution. Note saturation $>0.3 \mathrm{M}$. (b) Imaginary permittivity and model fit for frozen $4.73 \mathrm{M} \mathrm{NaCl}(23.5 \mathrm{wt} \%)$ solution at $181 \mathrm{~K} . \mathrm{H}_{2} \mathrm{O}$ relaxation is evident, but no distinct relaxation for $\mathrm{NaCl} \cdot 2 \mathrm{H}_{2} \mathrm{O}(22 \mathrm{vol} \%)$ was identified.
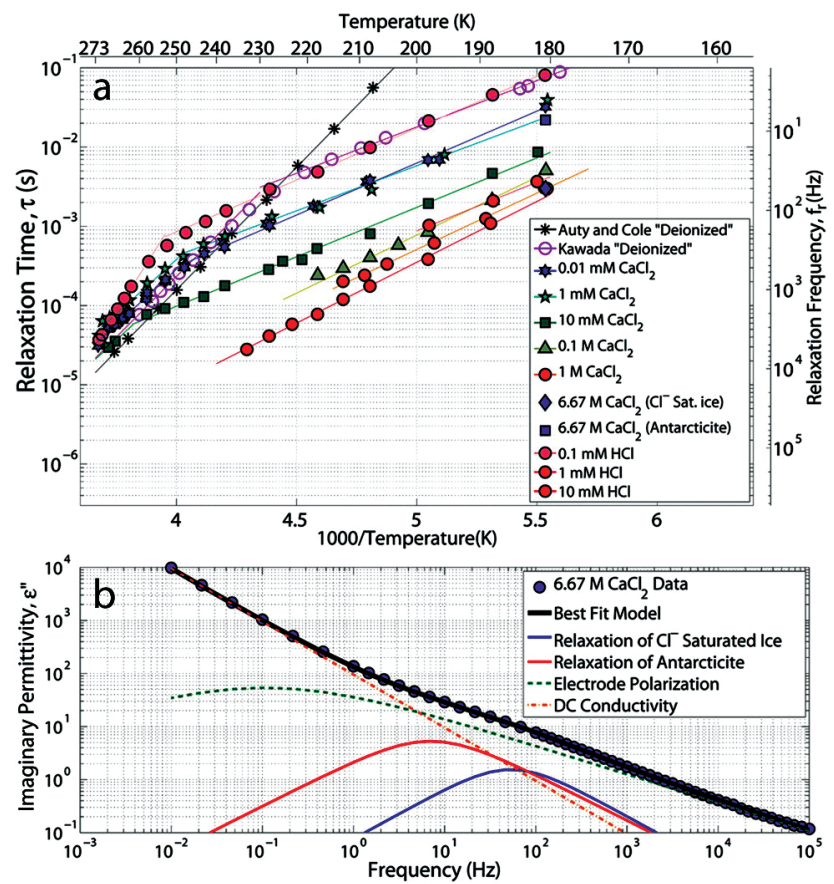

Figure 10. (a) Relaxation times for $\mathrm{CaCl}_{2}$-doped ice and $\mathrm{CaCl}_{2} \cdot 6 \mathrm{H}_{2} \mathrm{O}$ as functions of temperature and initial solution salt concentration, compared to pure ice and $\mathrm{HCl}$-doped ice. (b) Imaginary permittivity of frozen $6.67 \mathrm{M} \mathrm{CaCl}_{2}\left(49 \mathrm{wt} \%\right.$ ) solution at $180.5 \mathrm{~K}$, showing $\mathrm{H}_{2} \mathrm{O}$ and $\mathrm{CaCl}_{2} \cdot 6 \mathrm{H}_{2} \mathrm{O}$ relaxations in the presence of strong DC conductivity and electrode polarization. Antarcticite comprises $92 \mathrm{vol} \%$ in this sample.

$\mathrm{Cl}^{-}$partition coefficient $k \approx 4 \times 10^{-4}$ for $\mathrm{NaCl}$ solutions. At these small concentrations we are able to neglect the salt enhancement that occurs in the excluded liquid with which the ice equilibrates. Therefore $k$ for $\mathrm{NaCl}$ is generally smaller than
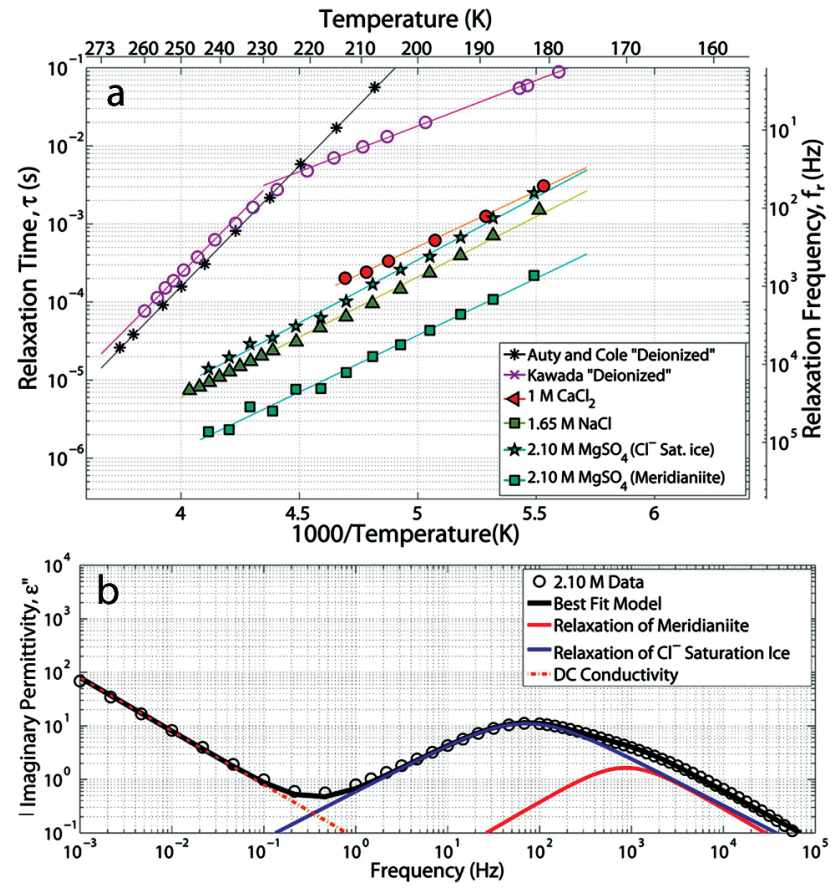

Figure 11. (a) Relaxation times for frozen, concentrated (2.1 M or 21 wt \%) $\mathrm{MgSO}_{4}$ solution, attributable to chloride impurities. (b) Imaginary permittivity at $182 \mathrm{~K}$, showing $\mathrm{H}_{2} \mathrm{O}$ and $\mathrm{MgSO}_{4} \cdot 11 \mathrm{H}_{2} \mathrm{O}$ relaxations. Meridianiite comprises $42 \mathrm{vol} \%$ in this sample.

values derived previously for $\mathrm{HCl}: 3 \times 10^{-3}$ (concentrationindependent ${ }^{12}$ ), $3 \times 10^{-4}$ to $4 \times 10^{-2}$ (concentration dependent $^{31}$ ), and $2.5 \times 10^{-3}$ ( single concentration ${ }^{9}$ ).

The same calculation for frozen $\mathrm{CaCl}_{2}$ solutions implies an ice extrinsic/intrinsic L-defect ratio $\sim 10$, a saturation $\mathrm{Cl}^{-}$ concentration $0.03 \mathrm{mM}$, and $k \approx 5 \times 10^{-5}$. Here we projected the saturated $\mathrm{CaCl}_{2}$ trend (Figure $10 \mathrm{a}$ ) to $\tau=23 \mu \mathrm{s}$ at $253 \mathrm{~K}$, as this reference mobility ${ }^{1}$ is above the eutectic melting point for the $\mathrm{CaCl}_{2}-\mathrm{H}_{2} \mathrm{O}$ system.

For $\mathrm{MgSO}_{4}$ solutions, saturation $\tau=8 \mu \mathrm{s}$ at $253 \mathrm{~K}$ (Figure 11a), very close to the value for $\mathrm{NaCl}$ solutions, yields an ice extrinsic/intrinsic L-defect ratio $\sim 30$. Neither $\mathrm{Mg}^{2+}$ nor $\mathrm{SO}_{4}{ }^{2-}$ is able to substitute in the ice lattice, so other impurities must form L-defects. Recall that the reagent grade $\mathrm{MgSO}_{4}$ contained up to $0.4 \mathrm{wt} \%$ chloride in concentrated solutions. The solution chloride concentration of $0.1 \mathrm{M}$ is consistent with the saturation solutions for other salts discussed above. A saturation $\mathrm{Cl}^{-}$ concentration in the ice of $0.08 \mathrm{mM}$ follows.

4.3.2. Salt Hydrate. Dielectric strengths $\varepsilon_{\mathrm{s}}-\varepsilon_{\infty}$ in the hydrate imply the presence of a dielectric relaxation (eq 5). At 180.5 $\mathrm{K}$, the $7-\mathrm{Hz} \mathrm{CaCl}_{2} \cdot 6 \mathrm{H}_{2} \mathrm{O}$ relaxation (Figure 10b) is distinct from the $60-\mathrm{Hz}$ chloride-saturated ice signature but more remarkably is separable from strong electrode polarization and $\sigma_{\mathrm{DC}}$ caused by this highly conductive hydrate. The antarcticite relaxation is strong because it is $92 \mathrm{vol} \%$ of the sample and has a large dielectric strength (see above). The $\mathrm{MgSO}_{4} \cdot 11 \mathrm{H}_{2} \mathrm{O}$ relaxation (Figure 11b) is clearly resolved at a decade higher in frequency, $900 \mathrm{~Hz}$, but is weaker than the ice relaxation (shifted slightly to $80 \mathrm{~Hz}$ ) because of the lower volumetric abundance of meridianiite $(42 \%)$ and the inferred smaller dielectric strength. The lack of a resolved dielectric strength for 26 vol \% $\mathrm{NaCl} \cdot 2 \mathrm{H}_{2} \mathrm{O}$ is manifested in Figure $10 \mathrm{~b}$ as a lack of dielectric relaxation other than that of ice at $70 \mathrm{~Hz}$.

All of the identified hydrate relaxations have $E_{\mathrm{a}} \approx 0.3 \mathrm{eV}$, very near that expected if L-defects are the majority charge carrier. Interfacial polarization can be ruled out because it should 
track the contrast caused by the large hydrate conductivity, which has $E_{\mathrm{a}} \approx 1 \mathrm{eV}$.

\section{Discussion: Defect Types and Concentrations}

5.1. Saline Ice. We suggest that the smaller partition coefficients and absolute chloride concentrations in ice formed from salt solutions are consequences of how the chloride enters the ice lattice. Some cation must be assimilated into the growing ice to charge balance the chloride incorporation into the lattice itself. It has been assumed that in salt solutions the anion takes a free hydronium and effectively enters the lattice as an acid. ${ }^{10}$ The required amount of $\mathrm{H}_{3} \mathrm{O}^{+}$is determined by the $\mathrm{Cl}^{-}$and the available $\mathrm{H}_{3} \mathrm{O}^{+}$is given by the solution $\mathrm{pH}$ and $k$.

For $\mathrm{NaCl}$ solutions, a chloride saturation concentration in ice of $0.1 \mathrm{mM}$ is equivalent to a $\mathrm{pH}$ of 4 . For any $k \ll 1$, this in turn would require a surrounding water $\mathrm{pH} \ll 4$ to supply sufficient hydronium to the growing ice crystals. The $\mathrm{pH}$ of our solutions was generally $\sim 5.7$, an expected value for equilibrium of carbonic acid with the atmosphere ${ }^{32}(\mathrm{pH}$ occasionally ranged as high as $\sim 10$ in highly concentrated $\mathrm{CaCl}_{2}$ solutions, probably due to $\mathrm{CaO}$ impurity; however, electrical properties did not change in titrations of these solutions to nominal $\mathrm{pH}$-see Figure 3b). In all cases it is clear that there is not enough $\mathrm{H}_{3} \mathrm{O}^{+}$in the solution to accompany chloride into the lattice on a one-to-one basis.

We conclude that the salt cations are accommodated interstitially to balance the chloride charge. This justifies the assumption above that chloride enters the lattice alone and supplies two L-defects. It also has the important implication that the static conductivity of salt-doped ice will always remain very small, because the minority charge carriers are hardly augmented $\left(\sigma_{\mathrm{L}} \gg \sigma_{+}\right)$. This is confirmed by our DC conductivity analysis above, which derived an average $\sim 5 \times 10^{-12} \mathrm{~S} \mathrm{~m}^{-1}$ for ice at $208 \mathrm{~K}$. Extrapolating to $253 \mathrm{~K}$ by using an average observed $E_{\mathrm{a}}=0.7 \mathrm{eV}$, Jaccard theory (essentially eqs 2 and 4 above, with parameters from Table 1) then requires an $\mathrm{H}_{3} \mathrm{O}^{+}$ defect concentration in the ice of $0.3 \mathrm{nM}\left(6 \times 10^{-12} / \mathrm{H}_{2} \mathrm{O}\right)$. At $k=3 \times 10^{-3}$, the parent solution could then have $\mathrm{pH}$ as high as 7.0. It is clear that the trace amounts of hydronium required to produce the small static conductivities of saline ice are easily acquired from the solutions from which the ice is grown.

Further support for dominant lattice substitution of chloride only comes from the static permittivity $\varepsilon_{\mathrm{s}}$. The dielectric strength - controlled by $\varepsilon_{\mathrm{s}}$ - has been observed for HCl-doped ice to fall to near zero twice with decreasing temperature. ${ }^{9}$ This "double crossover" is attributed to repeated switching of $\mathrm{H}_{3} \mathrm{O}^{+}$ vs L-defects as the majority charge carrier due to different mobilities and changing activation energies. Where either type of defect is dominant, $\Delta \varepsilon$ is proportional to $1 / T$. The fact that saline ice reproduces the "pure" ice curve, without any crossovers, then requires that the same defect type, $\mathrm{L}$, is the strong-majority charge carrier in both cases, and hence $\mathrm{Cl}^{-}$ defects greatly outnumber those due to $\mathrm{H}_{3} \mathrm{O}^{+}$.

Finally, consider polycrystalline ice grown from a $10 \mathrm{mM}$ $\mathrm{HCl}$ solution (Figure 10) for comparison. Taking $k=5 \times 10^{-3}$ at this concentration, ${ }^{31}$ the ice should contain $\sim 50 \mu \mathrm{M} \mathrm{HCl}$, or $9.8 \times 10^{-7} \mathrm{HCl} / \mathrm{H}_{2} \mathrm{O}$. As a strong acid, dissociated $\mathrm{HCl}$ will release both an $\mathrm{H}_{3} \mathrm{O}^{+}$and an L-defect into the ice. For our measured $\tau=9 \mu \mathrm{s}$ at $-20{ }^{\circ} \mathrm{C}$, Jaccard theory predicts $6.5 \times$ $10^{-7} \mathrm{HCl} / \mathrm{H}_{2} \mathrm{O}$ for equal numbers of $\mathrm{H}_{3} \mathrm{O}^{+}$and L-defects, in good agreement with the prediction. This is a crossover state, because $\sigma_{+}=8.2 \sigma_{\mathrm{L}}$ for equal defect abundances. The main purpose of this exercise, however, is to reinforce the conclusion that $\mathrm{H}_{3} \mathrm{O}^{+}$lattice substitution can only match specified impurity
TABLE 4: Salt Hydrate Defect Conductivities and Concentrations

\begin{tabular}{lcccr}
\hline \multicolumn{1}{c}{ hydrate } & $\begin{array}{c}\sigma_{ \pm} \\
\left(\mathrm{S} \mathrm{m}^{-1}\right)^{a}\end{array}$ & $\begin{array}{c}\sigma_{\mathrm{L}} \\
\left(\mathrm{S} \mathrm{m}^{-1}\right)^{a}\end{array}$ & $\begin{array}{c}r_{ \pm}^{b} \\
\left(\text { per } \mathrm{H}_{2} \mathrm{O}\right)^{c}\end{array}$ & $\begin{array}{c}r_{\mathrm{L}} \\
\left(\text { per } \mathrm{H}_{2} \mathrm{O}\right)^{c}\end{array}$ \\
\hline $\mathrm{CaCl}_{2} \cdot 6 \mathrm{H}_{2} \mathrm{O}$ & $6.2 \times 10^{-2}$ & $6.5 \times 10^{-2}$ & $1.7 \times 10^{-4}$ & $1.9 \times 10^{-3}$ \\
$\mathrm{NaCl}^{\circ} 2 \mathrm{H}_{2} \mathrm{O}$ & $7.8 \times 10^{-3}$ & $9.0 \times 10^{-3}$ & $2.9 \times 10^{-5}$ & $3.6 \times 10^{-4}$ \\
$\mathrm{MgSO}_{4} \cdot 11 \mathrm{H}_{2} \mathrm{O}$ & $<2.5 \times 10^{-3}<3.0 \times 10^{-3}<5.9 \times 10^{-6}<7.4 \times 10^{-5}$ \\
${ }^{a}-20{ }^{\circ} \mathrm{C} .{ }^{b}$ Assuming equal numbers of $\mathrm{H}_{3} \mathrm{O}^{+}$and L-defects; the \\
value is for the pair. ${ }^{c}$ Assuming defect mobility similar to ice.
\end{tabular}

levels when that impurity is a fully substitutable acid or base, and not a salt.

5.2. Salt Hydrates. We assume that electrical conduction in hydrates is protonic, like ice, from the existence of hydrogen bonds in the hydrates ${ }^{33,34}$ and because interfacial polarization associated with a change in conduction mode-analogous to electrode polarization-is not observed. In contrast to saline ice, the high static conductivities of the salt hydrates then require large numbers of both ionic and Bjerrum defects. We set $\sigma_{\mathrm{s}}=$ $\sigma_{\mathrm{DC}}$ and extrapolate to $253 \mathrm{~K}$ using activation energies $E_{\mathrm{a}}$ of $0.92 \mathrm{eV}$ for $\mathrm{CaCl}_{2} \cdot 6 \mathrm{H}_{2} \mathrm{O}$ and $1.1 \mathrm{eV}$ for $\mathrm{NaCl} \cdot 2 \mathrm{H}_{2} \mathrm{O}$ and $\mathrm{MgSO}_{4} \cdot 11 \mathrm{H}_{2} \mathrm{O}$ (again this must be done in lieu of direct measurement in our experiments due to the presence of brine channels above the eutectic melting temperature). The highfrequency conductivity is computed as $\sigma_{\infty}=\sigma_{\mathrm{s}}+\Delta \varepsilon / \tau$ (eq 6), but in practice $\sigma_{\mathrm{s}} \gg \Delta \varepsilon / \tau$ for the salt hydrates, so $\sigma_{\infty} \approx \sigma_{\mathrm{s}}$. Still, $\Delta \epsilon>0$. Defect conductivities (Table 4) follow from eqs 3 and 4 and defect concentrations, assuming defect mobilities in hydrate comparable to ice (Table 1), from eqs 1 and 2. The ionic defect concentration was computed assuming equal numbers of $\mathrm{H}_{3} \mathrm{O}^{+}$and $\mathrm{OH}^{-}$defects, which is argued immediately below. The defect concentrations also account for slightly different $N$ values $\left(\mathrm{H}_{2} \mathrm{O} / \mathrm{m}^{3}\right)$ for the different hydrates.

The derived concentrations are $10^{-6}-10^{-4} / \mathrm{H}_{2} \mathrm{O}$ for ionic defects and $10^{-5}-10^{-3} / \mathrm{H}_{2} \mathrm{O}$ for $\mathrm{L}$-defects. These are enormously higher than intrinsic defect concentrations for pure ice (Table 1), but are only up to a few orders of magnitude higher than saturation extrinsic defect concentrations for ice $(0.1 \mathrm{mM}=2$ $\times 10^{-6} / \mathrm{H}_{2} \mathrm{O}$ ). Abundant chloride-even as a trace contaminant in the meridianiite - can easily account for the L-defects. Again, however, $\mathrm{H}_{3} \mathrm{O}^{+}$or $\mathrm{OH}^{-}$cannot be derived directly from the solution; here it would require $\mathrm{pH}<-1$ or $>15$, respectively. Instead, we suggest that ionic defects are derived intrinsically from interaction of the salt and water during the early stages of hydrate formation. In the $\mathrm{MgSO}_{4}-\mathrm{H}_{2} \mathrm{O}$ system, the hydrogen bond between $\mathrm{H}_{2} \mathrm{O}$ and the sulfate oxygen is strong at low hydration numbers, ${ }^{35}$ which could lead to a simple acid-base reaction $\mathrm{MgSO}_{4} \cdot \mathrm{H}_{2} \mathrm{O}+\mathrm{H}_{2} \mathrm{O}=\mathrm{MgSO}_{4} \cdot \mathrm{H}_{3} \mathrm{O}^{+}+\mathrm{OH}^{-}$during hydrate accretion. This would release an ionic defect pair into the lattice, as assumed in the defect-concentration calculation. A similar process could apply to other salt hydrates because of the routine hydrogen bonding of $\mathrm{H}_{2} \mathrm{O}$ with the anion.

\section{Conclusions}

Broadband, capacitively coupled measurements of the complex electrical properties (permittivity and conductivity) of frozen saline solutions have elucidated the phase geometry and the type, abundance, and style of impurity uptake in saline ices and salt hydrates. The overall behavior is controlled by divisions imposed by the eutectic temperature and composition. Melt exists by definition above the eutectic temperature, but it does not form electrically interconnected channels until a threshold in the initial solution of $\sim 3 \mathrm{mM}$ is exceeded. This corresponds 
to micron-sized brine channels for 1-mm-diameter ice grains formed in the laboratory. The DC conductivity of the brines follows Archie's law with a form characteristic of welded grains surrounded by moderately tortuous fluid channels.

Below the eutectic temperature, the occurrence of ice and salt hydrate is uniquely determined by the initial salt content: below the eutectic composition, segregated ice is surrounded by the eutectic mixture of ice and hydrate, whereas above the eutectic composition, segregated hydrate is likewise surrounded by the eutectic mixture. Nonetheless, hydrate appears to be electrically interconnected, as evidenced by the general applicability of the Maxwell Garnett mixing model in this geometry applied to DC conductivity, static permittivity, and high-frequency permittivity. Power law mixing models that fit some parts of the data are more reminiscent of Archie's law and hence a more complex geometry, but the lack of isolation of the hydrate is evident everywhere.

A fundamental new conclusion of this work is that incorporation of a salt ion that is able to substitute into the ice lattice is not charge-balanced by $\mathrm{H}_{3} \mathrm{O}^{+}$or $\mathrm{OH}^{-}$from the liquid, but rather by interstitial accommodation of the salt counterion. In our specific experiments, $\mathrm{Cl}^{-}$does not take $\mathrm{H}_{3} \mathrm{O}^{+}$with it into the lattice, but $\mathrm{Na}^{+}$or $\mathrm{Ca}^{2+}$ is captured into interstices. Trace quantities of $\mathrm{H}_{3} \mathrm{O}^{+}$derived from the liquid do control the abundance of minority defects and hence the static conductivity.

Dielectric relaxations were detected for $\mathrm{CaCl}_{2} \cdot 6 \mathrm{H}_{2} \mathrm{O}$ (antarcticite) and $\mathrm{MgSO}_{4} \cdot 11 \mathrm{H}_{2} \mathrm{O}$ (meridianiite) but not for $\mathrm{NaCl} \cdot$ $2 \mathrm{H}_{2} \mathrm{O}$ (hydrohalite). The last result may simply be due to a relatively small volumetric abundance imposed by the experiments. The relatively high conductivity of the hydrates implies numerous protonic defects, assuming ice-like defect mobilities apply. These defect concentrations are rather larger than defectsaturated ice and may be intrinsic to hydrate formation.

Acknowledgment. This work was supported by NASA grants NNG05GN60G and NNG05GL88G to R.E.G., and by SwRI Internal Research. We thank Brianne Hamm for laboratory assistance.

\section{References and Notes}

(1) Petrenko, V. F.; Whitworth, R. W. Physics of Ice; Oxford University Press: Oxford, UK, 1999.
(2) Wolff, E. W.; Miners, W. D.; Moore, J. C.; Paren, J. G. J. Phys. Chem. 1997, 101, 6090.

(3) Addison, J. R. J. Appl. Phys. 1969, 40, 3105.

(4) Olhoeft, G. R. Can. J. Earth Sci. 1977, 14, 16. 39.

(5) Delaney, A. J.; Arcone, S. A. Cold Regions Sci. Technol. 1984, 9 ,

(6) Jaccard, C.; Thermoelectric effects in ice crystals, I. Theory of the steady state. Phys. Kondens. Mater. 1964, 1, 143-151.

(7) Johari, G. P.; Whalley, E. J. Phys. Chem. 1981, 75, 1333. 123.

(8) Camplin, G. G.; Glen, J. W.; Paren, J. G. J. Glaciol. 1978, 21,

(9) Takei, I.; Maeno, N. J. Chem. Phys. 1984, 81, 6186.

(10) Gross, G. W.; Hayslip, I. C.; Hoy, R. N. J. Glaciol. 1978, 21, 143.

(11) Kawada, S. J. Phys. Chem. Solids 1989, 50, 1177.

(12) Gross, G. W.; Wong, P. M.; Humes, K. J. Chem. Phys. 1977, 67, 5264

(13) Moore, J. C.; Reid, A. P.; Kipfstuhl, J. J. Geophys. Res. 1992, 99 , 5171.

(14) Dominé, F.; Thibert, E.; Van Landeghem, F.; Silvente, E.; Wagnon, P. Geophys. Res. Lett. 1994, 21, 601.

(15) Calcium Chloride Handbook; Dow Chemical Company: 2003.

(16) Grant, S. A. ERDC/CRREL TR-00-21, U.S. Army Cold Regions Res. and Eng. Lab., 2000.

(17) Peterson, R. C.; Wang, R. Geology 2006, 34, 957.

(18) Rupert, F. F. J. Am. Chem. Soc. 1909, 31, 851.

(19) CRC Handbook of Chemistry and Physics, 88th ed.; Lide, D. R., Ed.; CRC Press:Boca Raton, FA, 2008.

(20) Cory, D. G.; Ritchey, W. M. J. Magn. Reson. 1988, 80, 128.

(21) Wittebort, R. J.; Usha, M. G.; Ruben, D. J.; Wemmer, D. E.; Pines, A. J. Am. Chem. Soc. 1988, 110, 5668.

(22) Wettlaufer, J. S. Phys. Rev. Lett. 1999, 82, 2516.

(23) Wolff, E. W.; Paren, J. G. J. Geophys. Res. 1984, 89, 9433.

(24) Lesmes, D. P.; Friedman, S. P. In Hydrogeophysics; Water Science and Technology Library, Vol. 50; Rubin, Y.; Hubbard, S. S., Eds.; Springer: Dordrecht, The Netherlands, 2005.

(25) Price, P. B. Proc. Natl. Acad. Sci. U.S.A. 2000, 97, 1247.

(26) Sihvola, A. Electromagnetic Mixing Formulas and Applications; Electromagnetic Waves Ser. 47; Institution of Electrical Engineers: London, UK, 1999.

(27) McCarthy, C.; Cooper, R. F.; Kirby, S. H.; Durham, W. B. Lunar Planet. Sci. XXXVII 2006, \#2467.

(28) Auty, R. P.; Cole, R. H. J. Chem. Phys. 1952, 20, 1309.

(29) Johari, G. P.; Jones, S. J. Proc. Roy. Soc. London 1976, A349, 467.

(30) Kawada, S. J. Phys. Soc. Jpn. 1978, 44, 1881.

(31) Seidensticker, R. G. J. Chem. Phys. 1972, 56, 2853.

(32) Berner, E. K.; Berner, R. A. The Global Water Cycle; PrenticeHall: Englewood Cliffs, NJ, 1987.

(33) Bauer, W. H. Acta Cryst. 1964, 17, 1361.

(34) Agron, P. A.; Busing, W. R. Acta Crystallogr. 1986, C42, 141.

(35) Chaban, G. M.; Huo, W. M.; Lee, T. J. J. Chem. Phys. 2002, 117, 2532 .

JP8055366 